LBL-36510

$\mathrm{UC}-401$

\title{
Diffusion Behavior of Lysozyme in Aqueous Ammonium Sulfate Solutions under Varying Solution Conditions as Determined by Dynamic Light Scattering
}

\author{
Ursula M. Fornefeld, Daniel E. Kuehner, Harvey W. Blanch, and John M. Prausnitz* \\ Department of Chemical Engineering \\ University of California \\ and \\ Chemical Sciences Division \\ Lawrence Berkeley Laboratory \\ University of California \\ Berkeley, California 94720
}

December 1994

*Author to whom correspondence should be addressed. 


\section{Introduction}

As proteins gain significance in commercial applications such as pharmaceuticals, detergents, organic waste management and cosmetics, efficient and economical recovery of these valuable biomolecules is of increasing importance. The salting-out process has found widespread application in the area of protein separations [1]. To date, salt-induced precipitation of proteins from complex aqueous solutions remains largely an empirical process; no comprehensive model exists to predict salting-out phase equilibria in protein solutions. Rational predictive models for salt-induced precipitation will therefore be of great value in protein purification, both on the preparative and the analytical scale.

Any attempt to model theoretically salt-induced protein precipitation must include the known physics of protein interactions in aqueous solution. With this in mind, it is crucial to acknowledge that protein precipitation is fundamentally an aggregation process [19]. In order to incorporate aggregation effects into ongoing efforts to model salting out of proteins, it is necessary to quantify the degree of aggregation as a function of solution conditions (e.g., ionic strength and $\mathrm{pH}$ ). Therefore, dynamic light scattering measurements were performed with a well-studied protein, hen-egg-white lysozyme, under several solution conditions.

Dynamic light scattering (DLS) provides a powerful method for measuring size distributions of protein aggregates in solution and has been successfully applied to biological macromolecules [2]. Numerous reviews exist in the literature describing the experimental requirements of DLS and the methodology involved in data analysis [3-8]. Therefore, in the following section the theory of dynamic light scattering will be developed only as far as is needed for our purposes in this work. 


\section{DISCLAIMER}

This report was prepared as an account of work sponsored by an agency of the United States Government. Neither the United States Government nor any agency thereof, nor any of their employees, make any warranty, express or implied, or assumes any legal liability or responsibility for the accuracy, completeness, or usefulness of any information, apparatus, product, or process disclosed, or represents that its use would not infringe privately owned rights. Reference herein to any specific commercial product, process, or service by trade name, trademark, manufacturer, or otherwise does not necessarily constitute or imply its endorsement, recommendation, or favoring by the United States Government or any agency thereof. The views and opinions of authors expressed herein do not necessarily state or reflect those of the United States Government or any agency thereof. 


\section{DISCLAIMER}

Portions of this document may be illegible in electronic image products. Images are produced from the best available original document. 


\section{General Theory}

In a dynamic light scattering experiment, polarized laser light of a certain wavelength is focused on a small volume of solution. The light scattered by individual solute particles diffusing thermally into and out of this focal volume combines to produce a temporally varying net scattered intensity. The fundamental principle behind dynamic light scattering is that, since the intensity fluctuations are clearly determined by the time scale of the Brownian motion, those intensity fluctuations contain information about the dynamics of the scattering system, which can be described in terms of the diffusion coefficient. The signal generated by the scattered light of the diffusing particles can be analyzed by its intensity autocorrelation function

$$
\mathrm{G}^{\mathrm{I}}(\tau)=\langle\mathrm{I}(\mathrm{t}) \cdot \mathrm{I}(\mathrm{t}+\tau)\rangle
$$

where $I(t)$ is the intensity at time $t$ and $I(t+\tau)$ is the intensity at time $t+\tau$. The normalized electric field autocorrelation function, $\mathrm{g}^{\mathrm{E}}(\tau)$, is related to the normalized intensity autocorrelation function, $\mathrm{g}^{\mathrm{I}}(\tau)$, in the following manner:

$$
\mathrm{g}^{\mathrm{I}}(\tau)=\mathrm{A}\left[1+\mathrm{B}\left|\mathrm{g}^{\mathrm{E}}(\tau)\right|^{2}\right]
$$

where A and B are constants that depend on the sample and experimental conditions. The constant A is proportional to the square of the average scattered intensity, and B is an equipment parameter. For the case of random Brownian-motion diffusion of monodisperse spheres, described by Gaussian statistics, the electric field autocorrelation function $g^{E}(\tau)$ is a simple exponential:

$$
g^{E}(\tau)=\exp [-\Gamma \tau]
$$


The decay constant $\Gamma$ contains the information of interest. It is related to the apparent diffusion coefficient of the scattering spheres, $D_{\text {app }}$, by the following expression:

$$
\Gamma=\mathrm{q}^{2} \mathrm{D}_{\text {app }}
$$

where $q$ is the magnitude of the scattering vector, given by

$$
\mathrm{q}=\frac{4 \pi \mathrm{n}}{\lambda} \sin \left(\frac{\Theta}{2}\right)
$$

The scattering vector is a function of $\mathrm{n}$, the refractive index of the solution and $\lambda$, the wavelength of the scattered light, and $\Theta$, the angle of detection (see Figure 1a).

For a polydisperse sample, $\mathrm{g}^{\mathrm{E}}(\tau)$ is a sum of decaying exponentials weighted by the intensity of light scattered from particles of each characteristic size, and can be written as:

$$
\mathrm{g}^{\mathrm{E}}(\tau)=\int_{0}^{\infty} F(\Gamma) \exp (-\Gamma \tau) \mathrm{d} \Gamma
$$

where $F(\Gamma)$ represents the intensity-weighted distribution of decay constants.

To analyze this autocorrelation function the cumulant analysis procedure developed by Koppel [9], in which the exponential in eq. 6 is expanded as a power series of the delay time, was used:

$$
\ln \left|g^{\mathrm{E}}(\tau)\right|=-\bar{\Gamma} \tau+\mu_{2} \frac{\tau^{2}}{2 !}-\mu_{3} \frac{\tau^{3}}{3 !}+\ldots
$$


Here $\bar{\Gamma}$ is the mean decay rate from which an average apparent diffusion coefficient

$$
\overline{\mathrm{D}}_{\mathrm{app}}=\frac{\bar{\Gamma}}{\mathrm{q}^{2}}
$$

can be calculated. $\mu_{2}$ is called the second moment and is defined as:

$$
\mu_{2}=\overline{\mathrm{D}}^{2}-\overline{\mathrm{D}}^{2}
$$

which is the variance of the average diffusion coefficient distribution.

The relative second moment

$$
\mathrm{Q}=\frac{\mu_{2}}{\bar{\Gamma}^{2}}=\frac{\overline{\mathrm{D}}^{2}-\overline{\mathrm{D}}^{2}}{\overline{\mathrm{D}}^{2}}
$$

is often used as a measure of polydispersity. For a clean sample, $Q$ is typically about 0.02 or less. 


\section{Experimental Materials and Methods}

Hen-egg-white lysozyme, 3x-crystallized, dialyzed and lyophilized (CAS\# 1265088-3, Lot 111H7010), was purchased from Sigma Chemical and used without further purification. Ammonium sulfate (CAS\# 7783-20-2) was obtained from Fisher Scientific. Distilled water was de-ionized and $0.22-\mu \mathrm{m}$ filtered through a Barnstead NANOpure system prior to use.

\section{Sample Preparation}

In a typical experiment, the following sample preparation protocol was followed. An ammonium sulfate solution was prepared at the desired ionic strength. Sufficient crystalline lysozyme was dissolved in three separate $10-\mathrm{ml}$ aliquots of the ammonium sulfate solvent to yield protein concentrations of 10,20 and $30 \mathrm{mg} / \mathrm{ml}$. The volume change of the solutions upon dissolving the protein was negligible for all these concentrations. Then the $\mathrm{pH}$ of the solutions was adjusted to the desired value with $\mathrm{H}_{2} \mathrm{SO}_{4}$ or $\mathrm{NH}_{4} \mathrm{OH}$ solutions of the same ionic strength as the $\left(\mathrm{NH}_{4}\right)_{2} \mathrm{SO}_{4}$ solvent. Usually, the volume of acid or base required to adjust the $\mathrm{pH}$ was very small. Since the pH-adjusting solutions consisted of the conjugate acid/base to $\left(\mathrm{NH}_{4}\right)_{2} \mathrm{SO}_{4}$ at the same ionic strength as the sample, no change in ionic strength occurred upon $\mathrm{pH}$ adjustment. At the conclusion of an experiment, the $\mathrm{pH}$ of each sample was checked and the protein concentration was measured via ultraviolet spectrophotometry.

The polar nature of water makes it a very good solvent for dust particles. However, the presence of dust, defined as any unwanted scatterer, limits the accuracy of dynamic light scattering experiments. Therefore, extreme care was taken to eliminate dust contamination during sample preparation. The sample cells used in the DLS 
measurements (Pyrex NMR tubes; 12-mm OD and 0.5-mm WT; Wilmad Glass, Inc.) were cleaned via the following procedure: the cells were soaked in concentrated $\mathrm{H}_{2} \mathrm{SO}_{4}$ for 30 minutes, followed by a water rinse and soaking in an oxidizing solution ( $2 \mathrm{M}$ $\mathrm{NaOH}$ plus $0.02 \mathrm{M} \mathrm{KMnO}_{4}$ ) for ten minutes, followed by rinsing with $2 \mathrm{M} \mathrm{HCl}$; finally, the cells were rinsed with $\sim 200$ volumes of clean, filtered NANOpure water (previously recirculated extensively through a $0.22-\mu \mathrm{m}$ nominal-pore-size membrane filter). The cells were then covered with a cap modified with inlet and outlet tubes, allowing the samples to be further filtered in situ via closed-loop recirculation, and the samples were loaded into the cells by syringe through a Millipore Millex GV filter $(0.1-\mu \mathrm{m}$ nominal pore size). Then the tubing loops were closed, sealing the system, and the samples were recirculated continuously for up to 30 minutes for further dust removal. If recirculation of the sample through the $0.1-\mu \mathrm{m}$ Millex filter did not yield a clean enough sample, the filter was exchanged for a $0.02-\mu \mathrm{m}$ nominal pore size Whatman Anotop 25 Plus ceramic filter and the sample was further recirculated. The final cell rinsing and sample loading steps were conducted in a laminar flow hood. Figure 1 shows a schematic of the cell assembly and the sample loading process.

\section{Dynamic Light Scattering Measurements}

Dynamic light scattering experiments were performed using the experimental apparatus illustrated in Figure 2. A Coherent Innova-90 Argon laser operating at a wavelength of $488 \mathrm{~nm}$ supplied the incident radiation. The laser beam was focused on the sample immersed in a refractive index-matching fluid (decahydronaphthalene, $\mathrm{n}=1.475$ ) maintained at $25.0 \pm 0.2^{\circ} \mathrm{C}$ with an external VWR 1160 temperature bath. The scattered light intensity, which was measured over the angular range $30^{\circ}$ to $90^{\circ}$ in tendegree increments, was monitored by a BI-EMI-9865 photomultiplier tube mounted on a BI-240SM multiangle goniometer (Brookhaven Instruments Corp., Holtsville, NY). The 
output from the PMT was sent to a BI-2030AT digital autocorrelator, which calculated the autocorrelation function in real time. Data collection, processing and analysis were controlled by software running on a PC. For statistical validity, each measurement had a duration of 10 minutes, and duplicate measurements were made at all conditions. Runs were rejected when the difference between the calculated and the measured baseline was more than 0.02 percent (indicating dust contamination) or the polydispersity factor $\mathrm{Q}$ was higher than 0.09 . The majority of the runs had a baseline agreement within the order of 0.005 percent or better and a polydispersity between 0.01 and 0.04 .

\section{Refractive Index Measurements}

The refractive index of each sample was required for DLS data analysis. Refractive indices were measured with an Abbé refractometer (Zeiss). Figure 3 illustrates the dependence of solution refractive index on lysozyme concentration in ammonium sulfate solutions of $0.05 \mathrm{M}$ and $3.0 \mathrm{M}$ ionic strength. Refractive indices increased linearly with protein concentration. Typical refractive increments were the order of $0.2 \mathrm{ml} / \mathrm{g}$. These values are in good agreement with those found by laser differential refractometry at $632.8-\mathrm{nm}$ wavelength [10].

\section{Protein Concentration Measurements}

Lysozyme concentration in each sample was determined via ultraviolet spectrophotometry (using a Shimadzu UV-160 spectrophotometer) immediately after the conclusion of the DLS experiment. The extinction coefficient of lysozyme at $280 \mathrm{~nm}$ is $2.635 \mathrm{~L} /(\mathrm{g}-\mathrm{cm})[11]$. The $\mathrm{pH}$ of each sample was also measured directly after the experiment, using a Sargent Welch Model $8400 \mathrm{ion} / \mathrm{pH}$ meter with a Fisher Scientific glass combination electrode. It was found that the degree of sample filtration required for 
sufficient dust removal often caused a minor decrease in protein concentration $(\sim 1 \mathrm{~g} / \mathrm{L})$ and a small shift in the original sample $\mathrm{pH}(\sim 0.1 \mathrm{pH}$ unit).

\section{Data Acquisition and Data Reduction}

Dynamic light scattering measurements were conducted for lysozyme in ammonium sulfate as a function of solution ionic strength, $\mathrm{pH}$ and angle of detection. Data was collected for ionic strength $0.05 \mathrm{M}, 1 \mathrm{M}$ and $3 \mathrm{M}$ over the $\mathrm{pH}$ range 4-7. At each $\mathrm{pH}$ and ionic strength the autocorrelation function was measured for three protein concentrations $(\sim 10 \mathrm{~g} / \mathrm{L}, \sim 20 \mathrm{~g} / \mathrm{L}$ and $\sim 30 \mathrm{~g} / \mathrm{L})$ over the scattering angles $30^{\circ}$ to $90^{\circ}$ in ten-degree increments. Employing the second-order cumulant analysis described above, the average apparent diffusion coefficient $\overline{\mathrm{D}}_{\mathrm{app}}$ as a function of protein concentration and scattering angle was calculated from eq. 8 , truncating the series in eq. 7 after the second term. To obtain the diffusion coefficient at infinite dilution $\mathrm{D}_{0}$ for a given $\mathrm{pH}$ and ionic strength from $\bar{D}_{\text {app }}$, the method of the dynamic Zimm plot [12] was used. As shown in Figure $4, \bar{D}_{\text {app }}$ was plotted as a function of protein concentration, $c_{p}$, and scattering vector q. The average apparent diffusion coefficients, $\bar{D}_{\text {app }}(q, c)$, were extrapolated to $q=0$ and $c_{p}=0$. The intercept on the $y$-axis is equal to $D_{0}$ at that ionic strength and $p H$. The plotting constant $\mathrm{k}$ was chosen arbitrarily as $10^{9}$ for convenience; it has no physical meaning. In this manner, the infinite dilution diffusion coefficients $D_{0}$ of lysozyme, plotted in Figure 5, were determined for each $\mathrm{pH}$ and ionic strength studied. 


\section{$\underline{\text { Results and Discussion }}$}

\section{Infinite Dilution Quantities}

As shown in Figure 5, $D_{0}$ shows an inverse dependence on ionic strength. The decrease of $\mathrm{D}_{0}$ with increasing ionic strength is mainly due to the increasing viscosity of the solvent. This can be shown by relating the diffusion coefficient at infinite dilution $\mathrm{D}_{0}$ to the friction factor $\mathrm{f}$ by:

$$
D_{0}=\frac{k T}{f}
$$

where $\mathrm{k}$ is Boltzmann's constant and $\mathrm{T}$ the absolute temperature. For spherical, monodisperse particles $\mathrm{f}$ can be described by the simple Stokes-Einstein formula:

$$
f=6 \pi \eta_{0} r_{0}
$$

where $\eta_{0}$ is the viscosity of the solvent and $r_{0}$ the hydrodynamic radius of the macromolecule at infinite dilution. Crystal structure data indicate that lysozyme is ellipsoidal with approximate dimensions $30 \times 30 \times 45 \AA$ [13]. The following form for the friction factor of prolate ellipsoids is suggested by Perrin [14]:

$$
f=6 \pi \eta_{0} R\left(\frac{\left(z^{2}-1\right)^{1 / 2}}{z^{1 / 3} \ln \left[z+\left(z^{2}-1\right)^{1 / 2}\right]}\right)
$$

where $\mathrm{z}=\mathrm{a} / \mathrm{b}$, with $\mathrm{a}$ and $\mathrm{b}$ as the major and minor semiaxes, respectively, $(\mathrm{z}>1$ for prolate ellipsoids) and the effective spherical radius $R=\left(a b^{2}\right)^{1 / 3}$. However, the dependence of $f$ on axial ratio $a / b$ is found to be very weak. Very large deviations from 
sphericity are required to alter $f$ significantly from the value of eq. 11 . For monomeric lysozyme the value of $\mathrm{z}$ is 1.5 yielding a friction factor only 1.5 percent greater than the effective spherical approximation. Thus, for simplicity, it was decided to use the StokesEinstein equation for spheres when calculating infinite dilution hydrodynamic radius from $\mathrm{D}_{0}$ data. This choice is further justified by the fact that in all dynamic Zimm plots, $\overline{\mathrm{D}}_{\text {app }}$ showed almost no dependence on the angle of detection, suggesting that the lysozyme in solution was almost spherical.

Table 1 shows the hydrodynamic radius of lysozyme calculated from $D_{0}$ via the Stokes-Einstein equation. Tabulated values of the viscosity of aqueous ammonium sulfate solutions in the form of $\eta / \eta_{w}$ over a range of ammonium sulfate concentrations at $20^{\circ} \mathrm{C}$ were taken from the literature [15]. Here, $\eta_{w}$ is the viscosity of water at $20^{\circ} \mathrm{C}$ ( $\eta_{w}=1$ centipoise). Assuming that the ratio $\eta / \eta_{w}$ at $25^{\circ} \mathrm{C}$ is essentially the same as at $20^{\circ} \mathrm{C}$, we obtained our $\eta_{0}$ values by multiplying the tabulated ratios by the viscosity of water at $25^{\circ} \mathrm{C}, \eta_{w}=0.89$ centipoise. This assumption leads to a slight uncertainty in $\eta_{0}$. However, our conclusions are not affected.

It can be seen from Table 1 that the infinite dilution hydrodynamic radius of lysozyme changes little as a function of $\left(\mathrm{NH}_{4}\right)_{2} \mathrm{SO}_{4}$ concentration. Although the measured infinite dilution diffusion coefficient decreases significantly at higher salt concentrations, the solvent viscosity shows a corresponding increase. The product of $\eta_{0} \cdot D_{0}$, and thus $r_{0}$, remains constant over the range of salt concentrations examined.

All the values of $r_{0}$ shown in Table 1 are 1-2 $\AA$ higher than the effective spherical radius of a lysozyme monomer, $R=17.2 \AA$. This value of $R$ is calculated from the crystal structure of lysozyme and does not incorporate hydration of the protein molecule, which is known to occur. A monolayer of water would increase the effective spherical radius by 
approximately $2 \AA$, which corresponds well with our measured values of the infinite dilution hydrodynamic radius. Also, our values of $\mathrm{r}_{0}$ agree well with those reported by Nicoli and Benedek [16] for lysozyme in $0.2 \mathrm{M} \mathrm{KCl}$. They calculated from DLS measurements $r_{0}=18.5 \AA$ over a $\mathrm{pH}$ range of 1.2 to 2.3 .

Table 1 shows that, at all ionic strengths, $\mathbf{r}_{0}$ increases slightly with increasing solution $\mathrm{pH}$. It is possible to attribute this result to a small degree of aggregation. As the $\mathrm{pH}$ approaches the isoelectric point of lysozyme $(\mathrm{pI}=10.5)$, the net positive charge on the protein decreases, diminishing the magnitude of the repulsive coulombic interactions between proteins. This allows for the formation of a very small number of aggregates. The measured values of $\bar{D}_{\text {app }}$ at various lysozyme concentrations incorporate these polydispersity effects, and hence the extrapolated $D_{0}$ (and therefore $r_{0}$ ) reflects the aggregation state of the system at a given $\mathrm{pH}$. It is important to note that in all our measurements, the relative second moment of the distribution of decay rates, $Q$, was small. Typical values of $\mathrm{Q}$ were between 0.01 and 0.04 , indicating slight but nonnegligible polydispersity. With DLS it is not presently possible to accurately quantify the polydispersity in terms of a distribution of monomers, dimers and other small oligomers, however, due to limitations in data analysis techniques.

\section{Apparent Diffusion Coefficients}

Examination of the average apparent diffusion coefficient, $\overline{\mathrm{D}}_{\text {app }}$, as a function of protein concentration gives a more detailed picture of the forces governing diffusion. In Figure $6, \bar{D}_{\text {app }}$ is plotted as a function of protein concentration at a constant detection angle of $90^{\circ}$. It can be seen that for ionic strength $1 \mathrm{M}$ and $3 \mathrm{M}$ the diffusion coefficient decreases with increasing protein concentration at all values of $\mathrm{pH}$. The most probable cause for the decrease in $\overline{\mathrm{D}}_{\mathrm{app}}$ is hydrodynamic interaction. Namely, neighboring solute 
molecules perturb the velocity of the solvent at the location of any given solute molecule, retarding its diffusion. This results in a lower measured value of $\bar{D}_{\mathrm{app}}$.

In Figure 6, we observe that the dependence of $\bar{D}_{\text {app }}$ on protein concentration exhibits a change in slope for decreasing $\mathrm{pH}$ at ionic strength $0.05 \mathrm{M}$. It is possible to attribute this result to the presence of electrostatic interactions between proteins. As $\mathrm{pH}$ decreases, lysozyme becomes more positively charged. At $0.05 \mathrm{M}$ ionic strength, coulombic interactions are not completely screened. Therefore, as $\mathrm{pH}$ decreases, the magnitude of the repulsive coulombic interaction between proteins increases. This leads to an increase in the observed apparent diffusion coefficient, since the particles experience acceleration due to this force. At $\mathrm{pH} 4.25$, as lysozyme concentration increases, the electrostatic effects outweigh the effects of hydrodynamic interactions,

The effect of electrostatic interactions on $\bar{D}_{\text {app }}$ is further illustrated in Figure 7 , where $\bar{D}_{\text {app }}$ for $30 \mathrm{~g} / \mathrm{L}$ lysozyme is plotted as a function of the scattering vector $\mathrm{q}^{2}$. At low ionic strength $\overline{\mathrm{D}}_{\text {app }}$ shows significant dependence on $\mathrm{pH}$, indicating that electrostatics strongly influence the diffusion of the protein. This effect is less at $1 \mathrm{M}$, and for the $3 \mathrm{M}$ solutions the data for $\mathrm{pH} 4$ and $\mathrm{pH} 7$ coincide; coulombic interactions are fully screened. Again, note that the large differences in $\overline{\mathrm{D}}_{\text {app }}$ between different ionic strengths result from changes in solvent viscosity. However, in Figure 6 we have shown only $\bar{D}_{\text {app }}$ and not $\eta \cdot \bar{D}_{\text {app }}$, in order to highlight the effects of the $\mathrm{pH}$-dependent electrostatic interactions at each ionic strength. 


\section{Conclusion}

Our measurements showed that lysozyme is a hydrated monomer in solutions of ammonium sulfate at ionic strengths from $0.05 \mathrm{M}$ to $3 \mathrm{M}$ and $\mathrm{pH}$ ranging from 4 to 7 . The diameter of lysozyme calculated from the zero-angle, infinite-dilution extrapolated diffusion coefficient $D_{0}$ is insensitive to changes in ionic strength and $\mathrm{pH}$ within this range. For lysozyme concentrations up to $30 \mathrm{~g} / \mathrm{L}$ and ionic strengths up to $3 \mathrm{M}$, no conclusive evidence indicating significant aggregation was found.

These results are similar to those observed bovine pancreatic trypsin inhibitor (BPTI), which was also found to remain a monomer in similar solution conditions [17]. However it stands in contrast to findings for chymotrypsinogen, which is reported to aggregate greatly [18] and $\alpha$-chymotrypsin, which in preliminary studies showed a considerable amount of aggregation as $\mathrm{pH}$ approached the isoelectric point. Different globular proteins behave very differently under the same solution conditions; this must be taken into account when modeling phase equilibria of proteins.

\section{Acknowledgments}

This work was supported by the Director, Office of Energy Research, Office of Basic Energy Sciences, Chemical Sciences Division of U.S. Department of Energy under contract DE-AC03-76SF00098 and by the National Science Foundation. U. Fornefeld is grateful for a scholarship from the DAAD granted under the HSPIVAufe program. 


\section{Literature Cited}

1. Shih, Y.-C., Prausnitz, J. M., and Blanch, H. W., Biotech. Bioeng. 40, 1155, (1992).

2. Bloomfield, V. A., in "Dynamic Light Scattering: Application of Photon Correlation Spectroscopy” (R. Pecora), Plenum Press, New York, 1985.

3. Pecora, R., Ed., "Dynamic Light Scattering: Applications of Photon Correlation Spectroscopy", Plenum Press, New York, 1985.

4. Schmitz, K. S., "An Introduction to Dynamic Light Scattering by Macromolecules", Academic Press, Inc., New York, 1990.

5. Brown, W., Ed., "Dynamic Light Scattering: The Method and some Applications", Monographs on the Physics and Chemistry of Materials, vol. 49, Clarendon Press, Oxford, 1993.

6. Stanley-Wood, N. G., and Lines, R. W., Eds., "Particle Size Analysis", The Royal Society of Chemistry, Cambridge, 1992.

7. Provder, T., Ed., "Particle Size Distribution: Assessment and Characterization", ACS Symposium Series, vol. 332, American Chemical Society, Washington, DC, 1987.

8. Barth, H. G., Ed., "Modern Methods of Particle Size Analysis", Chemical Analysis, vol. 73, John Wiley \& Sons, New York, 1984.

9. Koppel, D. E., J. Chem. Phys. 57, 4814 (1972).

10. personal communication; Coen, C., (1994).

11. Sophianopoulos, A. J., Rhodes, C. K., Holcomb, D. N., and Holde, K. E. V., J. Biol. Chem. 237, 1107 (1962).

12. Wenzel, M., Burchard, W., and Schätzel, K., Polymer 27, 195 (1986).

13. Stryer, L., "Biochemistry." W. H. Freeman, New York, 1988.

14. Perrin, F., J. Phys. Radium 7, 1 (1936).

15. "CRC Handbook of Chemistry and Physics", 66th ed., The Chemical Rubber Co., Cleveland, OH, 1985.

16. Nicoli, D. F., and Benedek, G. B., Biopolymers 15, 2421 (1976).

17. Gallagher, W. H., and Woodward, C. K., Biopolymers 28, 2001 (1989).

18. Brandts, J. F., J. Amer. Chem. Soc. 86, 4291 (1964).

19. Rothstein, F., "Differential Precipitation of Proteins," in Protein Purification Process Engineering, R. G. Harrison, Ed., Marcel Dekker, New York, 115 (1994). 


\begin{tabular}{|ccc|}
\hline $\mathrm{pH}$ & $\mathrm{D}_{0} \times 10^{6}\left(\mathrm{~cm}^{2} / \mathrm{sec}\right)$ & $\mathrm{r}_{0}(\mathrm{~A})$ \\
\hline \hline $\mathrm{I}=0.05 \mathrm{M}$ & & \\
\hline 4.25 & 1.298 & 18.82 \\
6.1 & 1.263 & 19.34 \\
6.97 & 1.245 & 19.62 \\
$\mathrm{I}=1.0 \mathrm{M}$ & & \\
\hline 4.17 & 1.284 & 17.84 \\
5.17 & 1.256 & 18.24 \\
6.13 & 1.247 & 18.37 \\
6.9 & 1.219 & 18.79 \\
$\mathrm{I}=3.0 \mathrm{M}$ & & 18.18 \\
\hline 4.15 & 1.114 & 18.91 \\
\hline 7 & 1.071 & \\
\hline
\end{tabular}

Table 1: Hydrodynamic radius of lysozyme obtained by the StokesEinstein equation 
$I(t)$

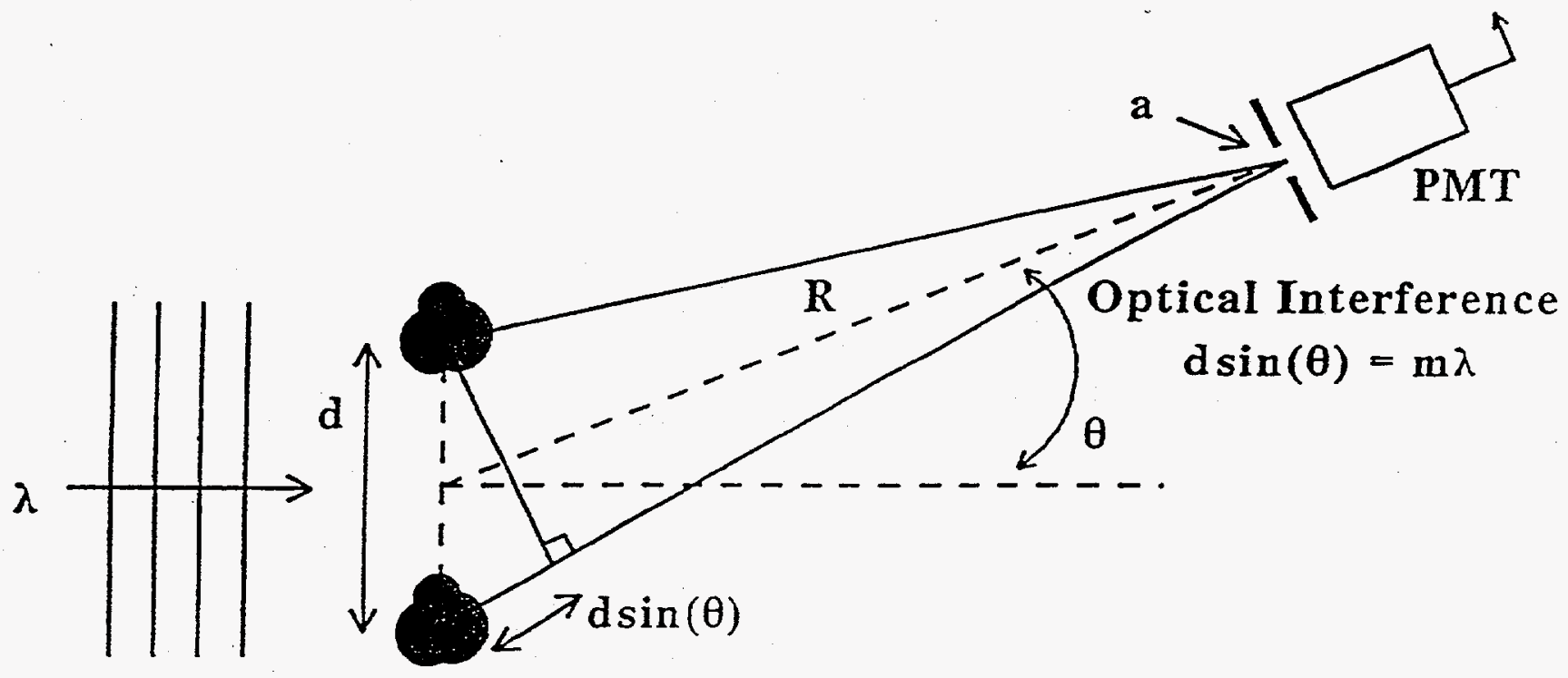

Fig. 1a: Angle of detection, $\theta$ 


\section{SAMPLE LOADING}

\section{IN-SITU RECIRCULATION}

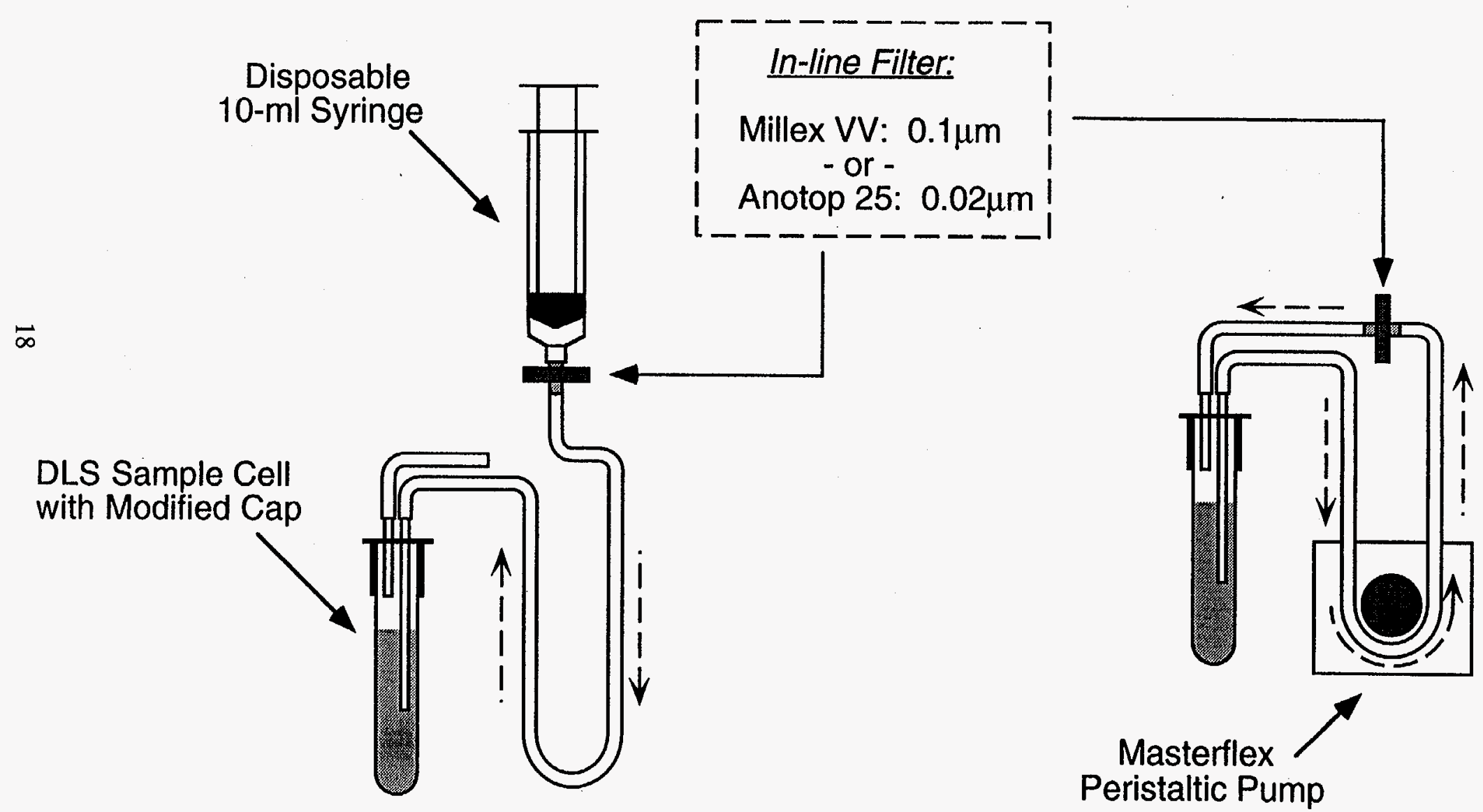

Figure 1: Sample loading/filtration apparatus and protocol 


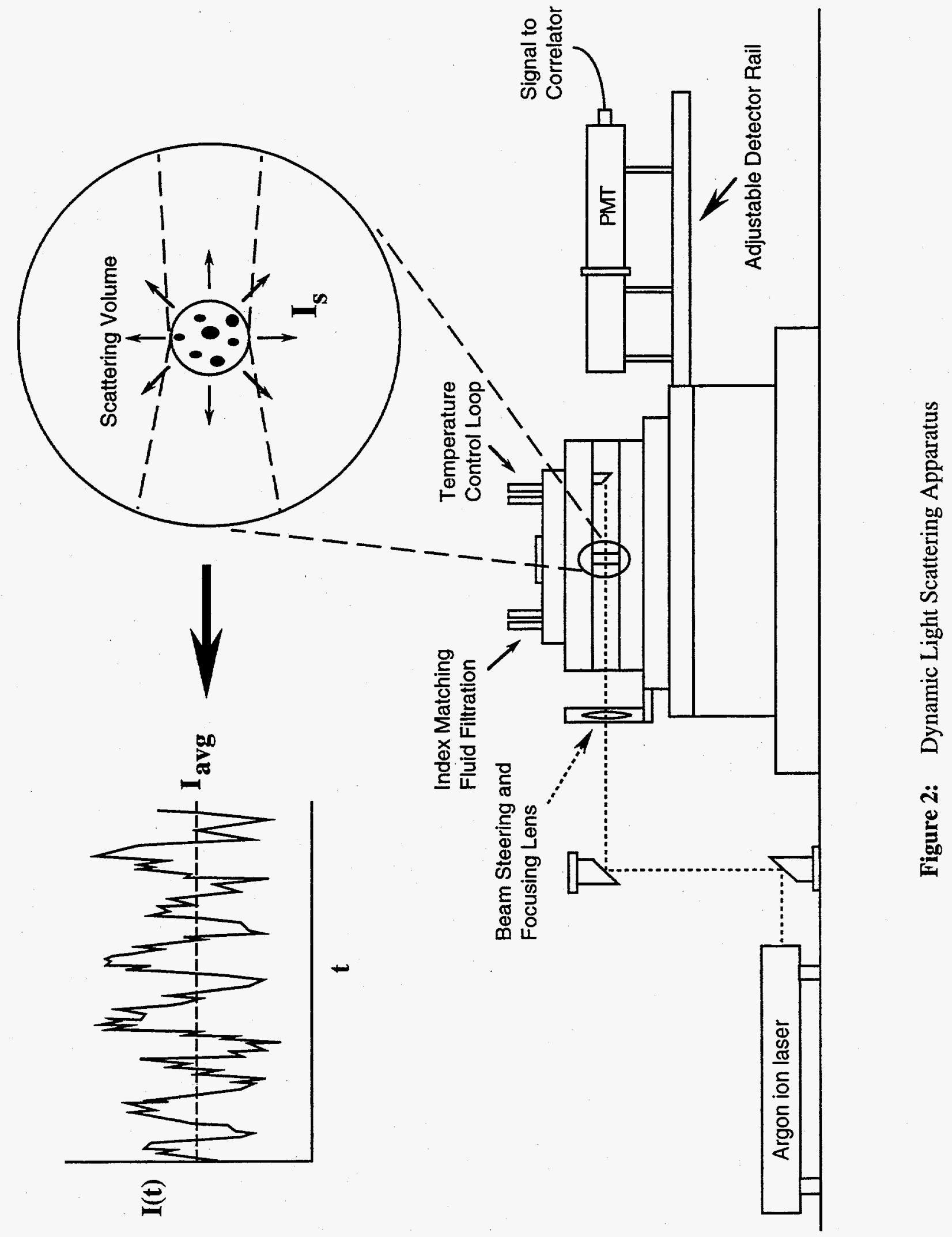




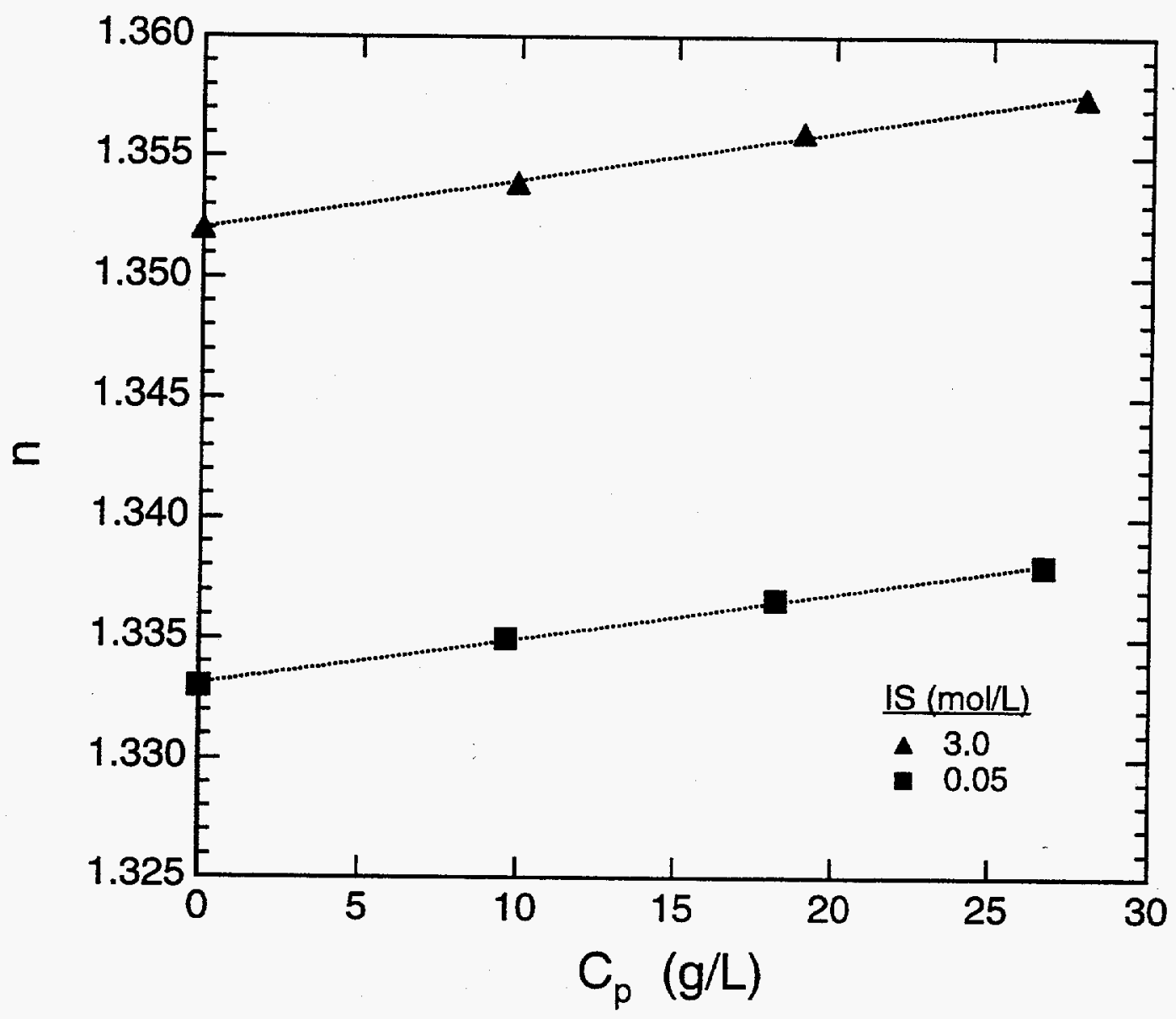

Figure 3: $\quad$ Refractive index of lysozyme in ammonium sulfate 


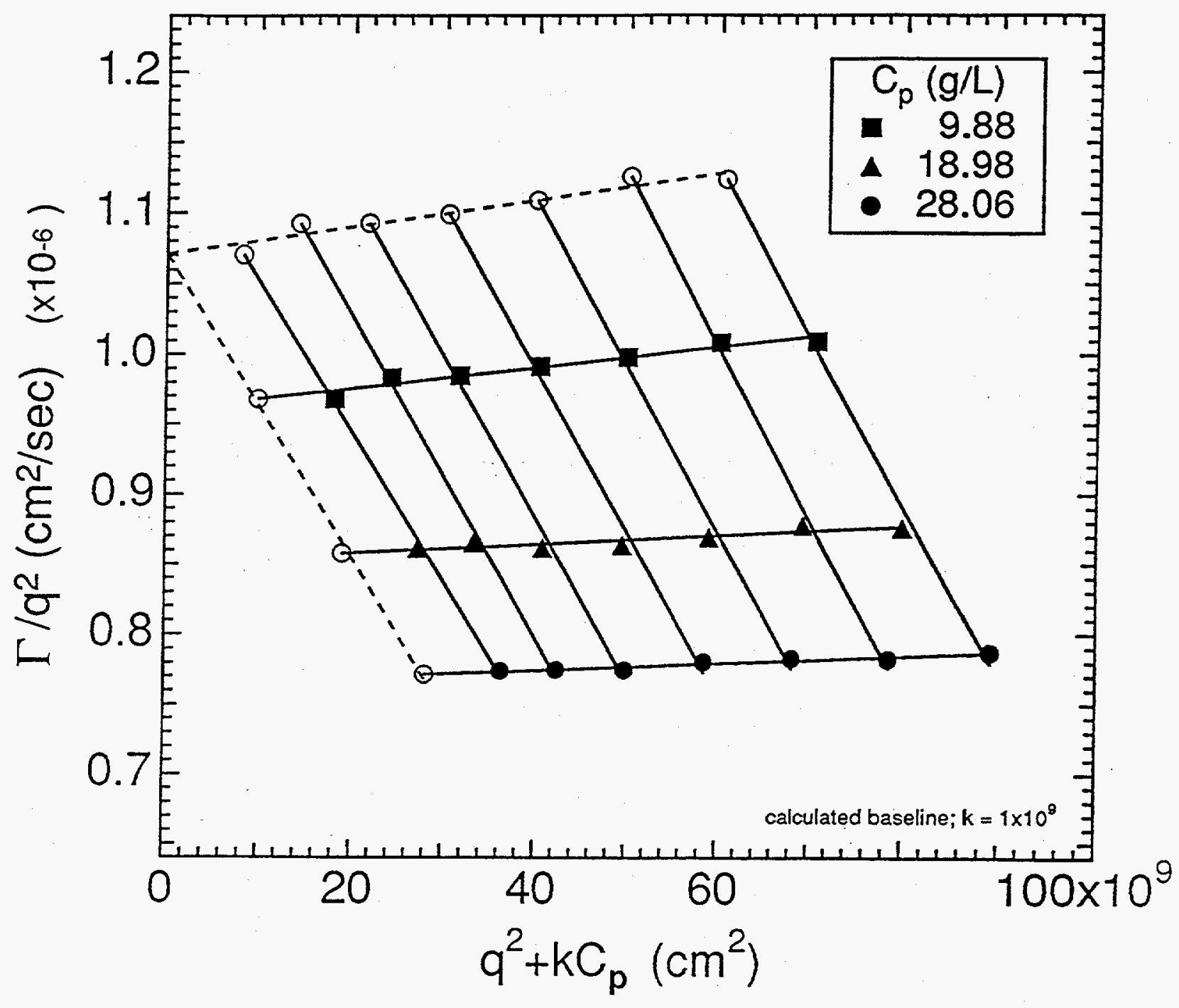

Figure 4: Dynamic Zimm plot for lysozyme in ammonium sulfate at $\mathrm{I}=3.0 \mathrm{M}$ and $\mathrm{pH} 7$ 


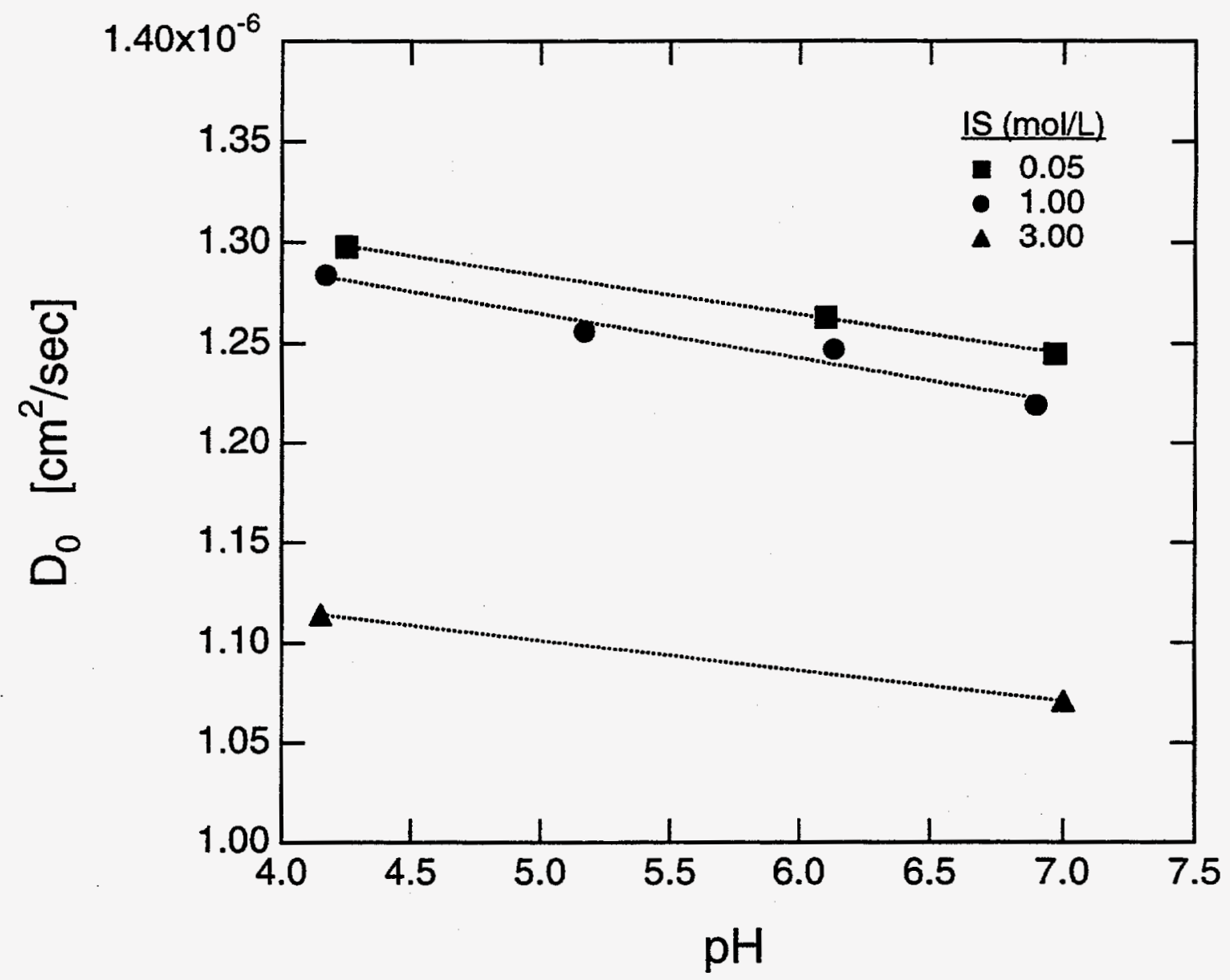

Figure 5: Infinite dilution coefficient $D_{0}$ of lysozyme in ammonium sulfate 


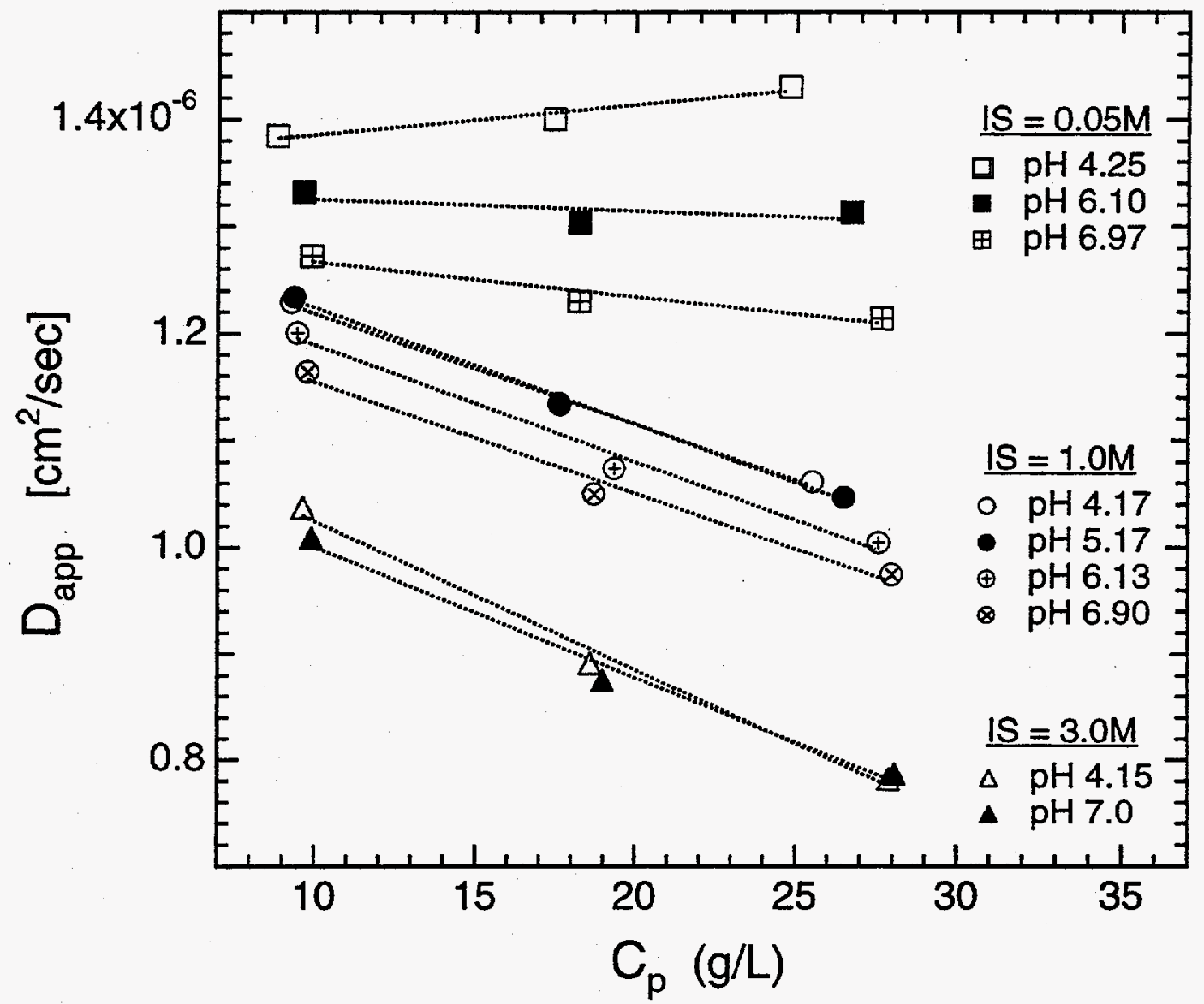

Figure 6: Average apparent diffusion coefficient $D_{\text {app }}$ of lysozyme in ammonium sulfate at $90^{\circ}$ scattering angle 


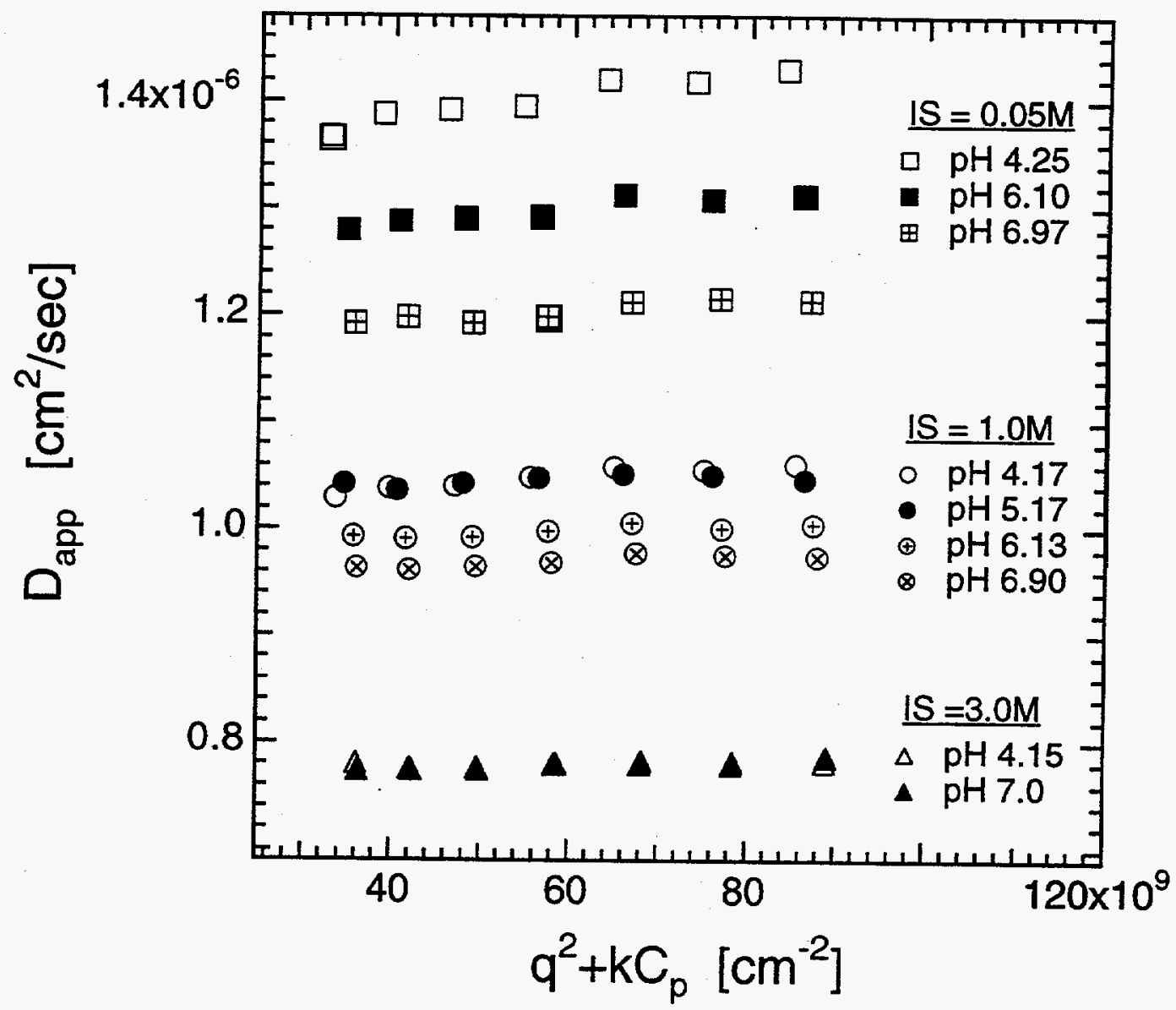

Figure 7: $\quad$ Average apparent diffusion coefficient $D_{\text {app }}$ of lysozyme $(30 \mathrm{~g} / \mathrm{L})$ in ammonium sulfate 